\author{
S. Samaropoulou, P. Bareka, R. Artelari \& G. Kamari
}

\title{
Karyological studies on some endemic and rare species of Kephalonia, Ionian Islands, Greece
}

\begin{abstract}
Samaropoulou, S., Bareka, P., Artelari, R. \& Kamari, G.: Karyological studies on some endemic and rare species of Kephalonia, Ionian Islands, Greece. — Fl. Medit. 23: 215-221. 2013. ISSN: 1120-4052 printed, 2240-4538 online.

The chromosome numbers and the karyotype morphology of five taxa originating from Kephalonia, Ionian Islands, are given. Regarding Saponaria aenesia, a karyotype analysis is reported here for the first time, while for Fritillaria mutabilis it is presented for the first time from Kephalonia island. The remaining data are in accordance with previous references for the respective taxa. Additionally, data for all studied taxa concerning their habitat and potential threats are discussed. Finally, an attempt is done to assess the conservation status of their populations and to suggest measures for their protection and sustainable management.

Key words: Karyotype analysis, Centaurea subciliaris, Cymbalaria microcalyx, Fritillaria mutabilis, Saponaria aenesia, Stachys parolinii, conservation status.
\end{abstract}

\section{Introduction}

Kephalonia is the largest island of the Ionian Islands (West Greece) and has a very rich flora. However, only 6 taxa have been found to be stenoendemic of the island [i.e. Ajuga orientalis subsp. aenesia (Heldr.) Phitos \& Damboldt, Limonium cephalonicum Artelari, Saponaria aenesia Heldr., Scutellaria rupestris subsp. cephalonica (Bornm.) Greuter \& Burdet, Silene cephallenia Heldr. subsp. cephallenia, Viola cephalonica Bornm.], while 61 are Greek endemic species (Katsouni \& al. 2009; Karagianni 2010; Katsouni 2012). Among other things, this implies that Kephalonia is an island, derived from the mainland rather than the sea. It is very significant that Kephalonia is the only island of Greece characterized by an Abies cephalonica fir forest, with Mt. Ainos being its 'locus classicus'. According to its floristic elements and their distribution, Kephalonia belongs to the Adriatic-Ionian phytogeographical region (Phitos \& Damboldt 1985).

So far, not many of the 1088 taxa, occurring on Kefalonia island have been investigated karyologically (Phitos \& Damboldt 1971, 1985; Kapasa \& al. 2001). This paper constitutes part of the first author's MSc thesis and it presents a karyological study on some endemic and rare species of this Greek island. The main aim of this thesis is to combine

\footnotetext{
* Extended and enriched version of the poster presented at the XIV Optima meeting in Palermo,
} 
information and comments about the karyology of some very important species with data about their habitat and potential threats. Finally, an attempt is being made to assess the conservation status of their populations and to suggest measures for their protection and sustainable management.

\section{Material and method}

Living plants or seeds of the investigated taxa (Table 1) were cultivated in the Experimental Botanic Garden of the University of Patras. The cytological study is based on the squash technique and the chromosome counts were made from root tip metaphases (Östergren \& Heneen 1962; Kamari 1976).

The root trips were pretreated in an aqueous solution of 8-hydroxyquinoline $(0,002 \%$ w/v) for 5-6 hours - in the case of Fritillaria mutabilis in a mixture of 1:1 8-hydroxyquinoline $(0,002 \% \mathrm{w} / \mathrm{v})$ : colchicine $(0.3 \mathrm{w} / \mathrm{v})$ for $3 \mathrm{hrs}$ (Kamari 1984) - and fixed in $3: 1$ (v/v) absolute ethanol:glacial acetic acid for 24 hours at $4{ }^{\circ} \mathrm{C}$. Fixed root tips were stored at $-20{ }^{\circ} \mathrm{C}$ at $75 \%$ ethanol for some days to months.

Before their use, the root tips were hydrolyzed in $1 \mathrm{~N} \mathrm{HCl} 60^{\circ} \mathrm{C}$ for $10-12 \mathrm{~min}$ and stained in Feulgen for 3 hrs (Darlington \& La Cour 1969). Prior to squashing, the stained root tips were put on a slide with a drop of $45 \%$ (v/v) acetic acid. The slides were observed and photos were taken with AXIOPHOT Zeiss microscope, equipped with a Leica digital camera.

Table 1: Alphabetical list of the investigated taxa with location and chromosome number $-*$ : first report; $\uparrow$ : first report of karyotype morphology.

\begin{tabular}{|l|l|l|}
\hline Taxon & Location & $\mathbf{2 n}$ \\
\hline Centaurea subciliaris & Mt. Ainos & $36+1 \mathrm{~B}$ \\
\hline Cymbalaria microcalyx subsp. minor & Mt. Ainos & 28 \\
\hline Fritillaria mutabilis & Mt. Roudi & $24^{\dagger}$ \\
\hline Saponaria aenesia & Mt. Ainos & $28^{*},{ }^{\dagger}$ \\
\hline Stachys parolinii & Mt. Roudi & 34 \\
\hline
\end{tabular}

\section{Results}

\section{Caryophyllaceae}

Saponaria aenesia Heldr. $-2 n=28$ (Fig. 1A).

Gr: Ionian Islands, Isl. Kephallinia, Mt. Ainos, $38^{\circ} 07^{\prime} 45^{\prime \prime} \mathrm{N}, 20^{\circ} 41^{\prime} 12^{\prime \prime} \mathrm{E}$, alt. 1367 m, 05 Jul 2009, Karagianni s.n. (seeds), Samaropoulou cult. no SK15 (UPA).

This is a stenoendemic species of Kephalonia island, located mainly on calcareous ground at 400-1500 m alt. A typical characteristic of its subpopulations' status is their 
sparse and interspersed distribution, thus never forming a large and united population (Katsouni \& al. 2009).

Saponaria aenesia has been characterized, according to the IUCN 2001 criteria, as an Endangered (EN) species, due to the above mentioned restricted and disjunct distribution, as well as the detection of very few mature individuals. The species is mainly subjected to fire threats and intense grazing (Katsouni \& al. 2009).

The chromosome number, $2 n=28$ and the karyotype morphology of Saponaria aenesia are recorded for the first time. The karyotype is diploid, symmetrical, consisting of mostly metacentric (m) chromosomes, ranging in size between 1.47 and $2.19 \mu \mathrm{m}$ (Fig. 1A).

\section{Compositae}

Centaurea subciliaris Boiss. \& Heldr. $-2 n=36+1 \mathrm{~B}$ (Fig. 1B).

Gr: Ionian Islands, Isl. Kephallinia, Mt. Ainos, 38 $08^{\prime} 24^{\prime \prime} \mathrm{N}, 20^{\circ} 39^{\prime} 33^{\prime \prime} \mathrm{E}$, alt. 1596 m, 16 Aug 2008, Karagianni s.n. (seeds), Samaropoulou cult. no SK12 (UPA).

Karaplianis \& Constantinidis (2009), in accordance to Matthäs (1976) suggested that the plants from the Ionian Islands (Kephalonia and Lefkada) belong to the typical subspecies of Centaurea subciliaris, while those from Akarnania (Sterea Ellas) to the subspecies acarnanica Matthäs, both taxa being endemic to their distributional areas. However, Greuter \& Raab-Straube (2008) raised subspecies acarnanica to species level and reported that $C$. subciliaris is also distributed in Bulgaria. More detailed study, using material from more localities and applying new karyological techniques will help elucidate the story behind this very interesting Centaurea group.

C. subciliaris occurs in calcareous places, uncultivated fields and at the edges of the roads. Most of Kephalonia's subpopulations are found at 400-600 m alt., however this species also sporadically appears on Mt. Ainos up to an altitude of $1600 \mathrm{~m}$.

Road widening and intense grazing are the main threats for the subpopulations of the taxon.

Previous chromosome reports refer to diploid $(2 n=18+2 \mathrm{~B})$ and tetraploid $(2 n=4 \mathrm{x}=36$ + 0-4B) chromosome numbers (Phitos \& Damboldt 1971, 1985). Our results from a sub-

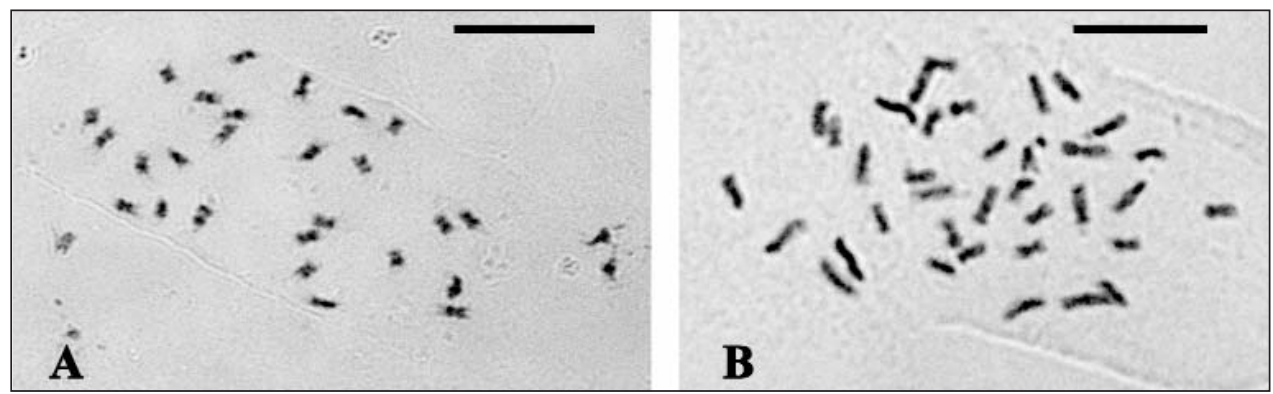

Fig. 1. Microphotographs of mitotic metaphase plates of: A. Saponaria aenesia, $2 n=28$; B. Centaurea subciliaris, $2 n=4 \mathrm{x}=36+1 \mathrm{~B}$. - Scale bars $=10 \mu \mathrm{m}$. 
population of Mt. Ainos are in agreement with the latter reports $(2 n=4 \mathrm{x}=36+1 \mathrm{~B}$-chromosomes). The karyotype is found to be symmetrical with metacentric (m) and submetacentric $(\mathrm{sm})$ chromosomes, ranging in size between 2.13-3.63 $\mu \mathrm{m}$. Moreover, the presence of one B-chromosome is observed, as well as a pair of SAT-chromosomes (Fig. 1B).

\section{Labiatae}

Stachys parolinii Vis. $-2 n=34$ (Fig. 2A).

Gr: Ionian Islands, Isl. Kephallinia, Mt. Roudi, $38^{\circ} 11^{\prime} 40^{\prime \prime} \mathrm{N}, 20^{\circ} 37^{\prime} 28^{\prime \prime}$ E, alt. 820 m, 01 Jul 2009, Karagianni s.n. (seeds), Samaropoulou cult. no SK17 (UPA).

Stachys parolinii is a Greek endemic species, which occurs in N Peloponnisos, Sterea Hellas and on Ionian Islands (Kephalonia and Lefkada). It is localized in calcareous grounds and open, rocky places with macchie and phrygana, at 10-900 m alt. (Phitos \& Damboldt 1985, Tan \& Iatrou 2001).

Intense grazing, especially outside the protected area of the Aenos National Park, is the main activity threating the subpopulations of the taxon.

The chromosome number $2 n=34$ agrees with the previous records for the species (Baltisberger \& Lenherr 1984). The karyotype is diploid and symmetrical, as far as morphology is concerned. The chromosomes range between 1.11 and $2.22 \mu \mathrm{m}$ (Fig. 2A).

\section{Liliaceae}

Fritillaria mutabilis Kamari $-2 n=24$ (Fig. 3).

Gr: Ionian Islands, Isl. Kephallinia, Mt. Roudi, at the summit area Gioupari, $38^{\circ} 11^{\prime}$ $08^{\prime \prime}$ N, 20³6' 56"' E, alt. 1050 m, 01 May 2013, Phitos \& Kamari 21775, Samaropoulou cult. no $S K 83$ (UPA).

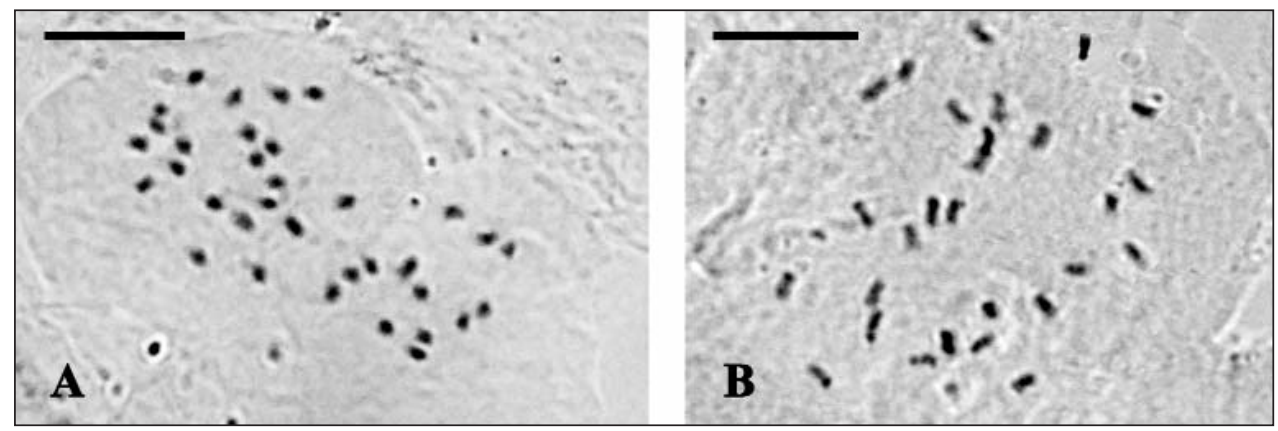

Fig. 2. Microphotographs of mitotic metaphase plates of: A. Stachys parolinii, $2 n=34$; B. Cymbalaria microcalyx subsp. minor, $2 n=28$. - Scale bars $=10 \mu \mathrm{m}$. 


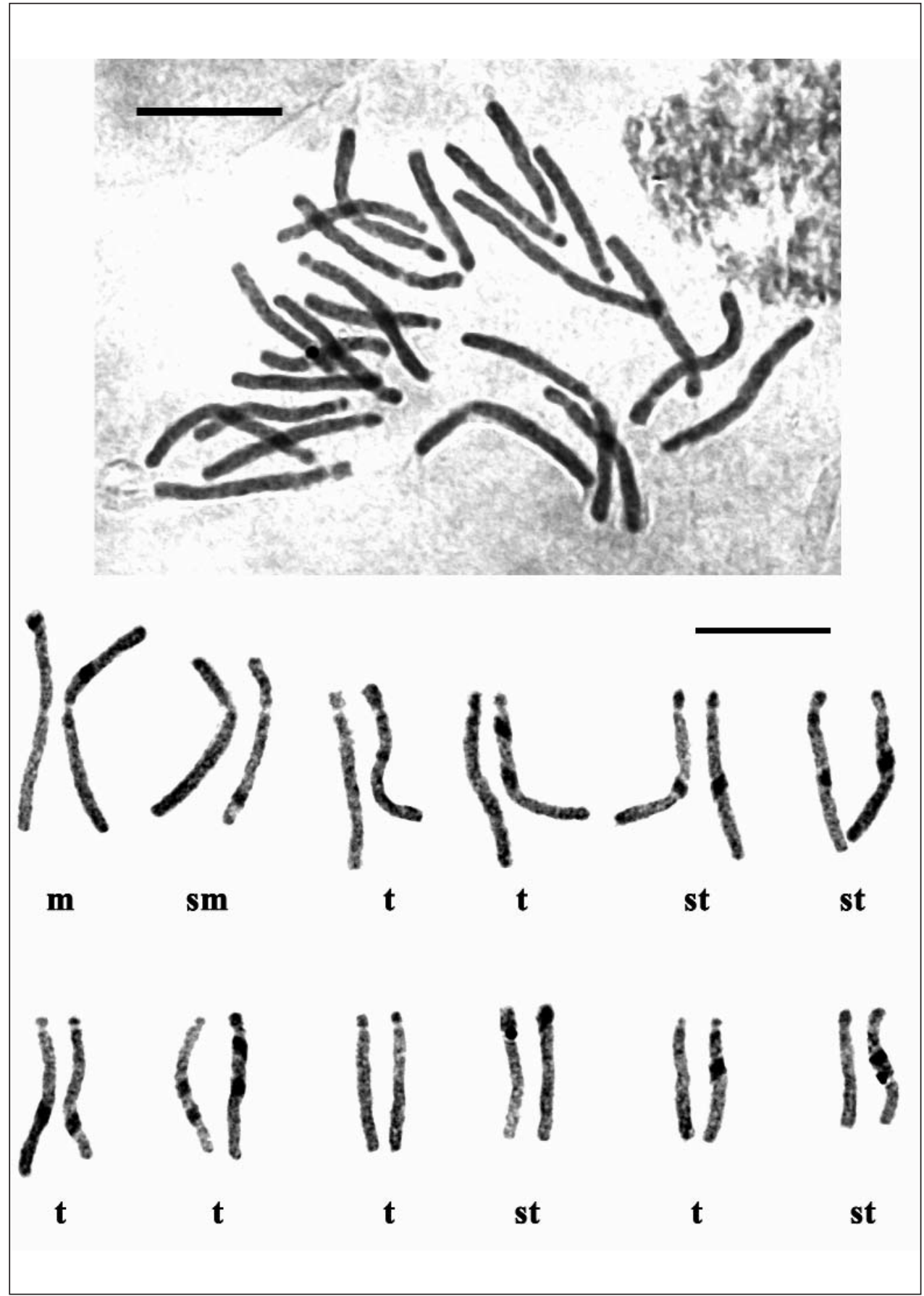

Fig. 3. Microphotograph of mitotic metaphase plates and karyogram of Fritillaria mutabilis, $2 n=24$. - Scale bars $=10 \mu \mathrm{m}$. 
This is a Greek endemic Fritillaria species, appearing on the mountains of $\mathrm{N}$ Peloponissos, Sterea Hellas, in S Pindos and on Ionian Islands (Kephalonia and Lefkada). It is found on rocky slopes with macchie or in montane to subalpine meadows and openings of Abies cephalonica forest. It prefers limestone, schist or rarely ophiolithic substrates, at (400-) 600-2100 m alt. (Kamari 1991a).

Fritillaria mutabilis is mainly threatened in Kefalonia due to the very intense grazing practices.

The karyotype of a subpopulation of Mt. Roudi consists of $2 n=2 \mathrm{~m}+2 \mathrm{sm}+6 \mathrm{st}+2 \mathrm{st}-$ $\mathrm{SAT}+12 \mathrm{t}=24$ chromosomes and it is diploid, asymmetrical, as far as its morphology is concerned. Chromosome size ranges between 10.8-19.5 $\mu \mathrm{m}$ (Fig. 3). Previous reports for the species demonstrate $2 n=24+0-2 \mathrm{~B}$, as well as an acrocentric pair of SAT-chromosomes, bearing very big and long satellites (Kamari 1991b).

\section{Scrophulariaceae}

Cymbalaria microcalyx (Boiss.) Wettst. subsp. minor (Cufod.) Greuter $-2 n=28$ (Fig. 2B).

Gr: Ionian Islands, Isl. Kephallinia, Mt. Ainos, $38^{\circ} 09^{\prime} 34^{\prime \prime} \mathrm{N}, 20^{\circ} 37^{\prime} 24^{\prime \prime}$ E, alt. 1073 m, 27 Jul 2008, Karagianni s.n. (seeds), Samaropoulou cult. no SK25 (UPA).

Cymbalaria microcalyx subsp. minor is an endemic taxon of Greece and its distribution includes Ionian Islands (Kefallinia), Peloponnissos and S Pindos. The species is localized in rock crevices or stony places, up to1950 m alt. (Raus 1991).

The chromosome number $2 n=4 \mathrm{x}=28$ agrees with previous reports for the subspecies by Damboldt \& Phitos (1971) and Speta (1986). Its karyotype is tetraploid and symmetrical, consisting of metacentric $(\mathrm{m})$ and submetacentric $(\mathrm{sm})$ chromosomes, varying in size between 1.33-2.67 $\mu \mathrm{m}$ (Fig. 2B).

\section{Acknowledgements}

We would like to thank the employees of the Management Body of the Aenos National Park for their important collaboration particularly in the form of support during plant collection and the provision of bulbs or seeds that were used in the karyological study.

\section{References}

Baltisberger, M. \& Lenherr, A. 1984: Neue Chromosomenzahlen aus der Gruppe der Stachys recta L. und anderen, verwandten Artengruppen. - Ber. Geobot. Inst. ETH Stiftung Rubel 51: 39-62.

Damboldt, J. \& Phitos, D. 1971: Reports. [In Love, Á. (ed.), IOPB Chromosome Number Reports XXXVI]. - Taxon 20: 787.

Darlington, C. D. \& La Cour, L. 1969: The Handling of Chromosomes. - London.

Greuter, W. 2003: The Euro+Med treatment of Cardueae (Compositae) - generic concepts and required new names. - Willdenowia 33: 49-63.

— \& Raab-Straube, E. von (eds) 2008: Med-Checklist, 2. - Palermo, Genève \& Berlin. 
IUCN 2001: IUCN Red List Categories and Criteria: version 3.1. - IUCN Species Survival Commission, Gland \& Cambridge.

Kamari, G. 1976: Cytotaxonomic study of the Crepis neglecta L. complex in Greece. - PhD Thesis, University of Patras, Patras.

- 1984: Caryosystematic studies of Fritillaria L. (Liliaceae) in Greece. 1. - Webbia 38: 723-731.

- 1991a: Fritillaria L. - Pp. 672-683 in: Strid, A. \& Tan, K. (eds.), Mountain Flora of Greece 2. Edinburgh.

- 1991b: The genus Fritillaria L. in Greece: taxonomy and karyology. - Bot. Chron. 10: 253-270. Kapasa, M., Nikolaidi, T., Bareka, E. P. \& Kamari, G. 2001: Reports (1236-1243). [In: Kamari, G., Blanché, C. \& Siljak-Yakovlev, S. (eds), Mediterranean chromosome number reports - 11]. Fl. Medit. 11: 448-454.

Karagianni, B. 2010: Management and protection of endemic, endangered and rare plants of National Park of Ainos, Kefalonia. - MSc Thesis, University of Patras, Patras.

Karamblianis, Th. \& Constantinidis, Th. 2009: Centaurea subciliaris Boiss. \& Heldr. subsp. acarnanica Matthas. - Pp. 253-255 in: Phitos, D., Constantinidis, Th. \& Kamari, G. (eds), The Red Data Book of Rare and Threatened Plants of Greece, 1(A-D). - Patras.

Katsouni, N. 2012: Human impacts on evolution of the flora and vegetation of Cephalonia since prehistoric times until today: a study for application in environmental education. - PhD Thesis, University of Patras, Patras.

-, Karagianni, B. \& Phitos, D. 2009: Scutellaria rupestris Boiss. \& Heldr. subsp. cephalonica (Bornm.) Greuter \& Burdet. - Pp. 294-296 in: Phitos D., Konstantinidis, Th. \& Kamari, G. (eds), The Red Data Book of Rare and Threatened Plants of Greece, 2(E-Z). - Patras.

—, Phitos, D., Kamari, G. \& Karagianni, B. 2009: Saponaria aenesia Heldr. - Pp. 285-286 in: Phitos D., Konstantinidis, Th. \& Kamari, G. (eds), The Red Data Book of Rare and Threatened Plants of Greece, 2(E-Z). - Patras.

Matthäs, U. 1976: Zur Cytotaxonomie von Centaurea subciliaris Boiss. \& Heldr. (Sektio Phalolepis (Cass.) DC.) und verwandter Sippen im europäischen Mediterrangebiet. I. - Bot. Jahrb. Syst. 95(4): 418-434.

Östergren, G. \& Heneen, W. K. 1962: A squash technique for chromosome morphological studies. Hereditas 48: 332-341.

Phitos, D. \& Damboldt, J. 1971: Beitrage zur Flora Ionica. - Ann. Naturhistor. Mus. Wien 75: 157162.

— \& - 1985: Die Flora der Insel Kefallinia (Griechenland). - Bot. Chron. 5 (1-2): 182-183.

Raus, Th. 1991: Cymbalaria Hill. - Pp. 206-207 in: Strid, A. \& Tan, K. (eds), Mountain Flora of Greece, 2. - Edinburgh.

Speta, F. 1986: Heterokarpidie, Dehiszenz, Heterospermie und basifixe Samen bei Cymbalaria Hill (Scrofulariaceae) und systimatische Schlussfolgerungen. - Phyton (Horn) 26: 23-57.

Tan, K. \& Iatrou, G. 2001: Endemic Plants of Greece: The Peloponnese. - Copenhagen.

Addresses of the authors:

Sophia Samaropoulou ${ }^{1}$, Pepy Bareka ${ }^{2}$, Rea Artelari ${ }^{1} \&$ Georgia Kamari ${ }^{1}$,

${ }^{1}$ Botanical Institute, Section of Plant Biology, Department of Biology, University

of Patras, 26500 Patras, Greece.

E-mails: s.samarop@gmail.com; artelari@upatras.gr; kamari@upatras.gr

${ }^{2}$ Laboratory of Systematic Botany, Faculty of Crop Science, Agricultural University

of Athens, Iera Odos 75, 11855 Athens, Greece. E-mail: bareka@aua.gr 
